\title{
Razonamiento jurídico: Lógica, interpretación y argumentación
}

Legal Reasoning: Logic, Interpretation and Argumentation

\author{
Mabell Abigail Lagla Pillajo
}

Investigadora Jurídica, Cevallos \& Noboa

Artículo Original (Revisión)

RFJ, No. 1, 2017, pp. 59-80, ISSN 2588-0837

RESUMEN: El presente trabajo investigará los aspectos más importantes de la lógica de lo razonable, en el cual la argumentación juega un papel fundamental mientras que la interpretación jurídica, no se encuentra ajena a ello. Además, se recurrirá al razonamiento jurídico, el cual pretende como fin último la búsqueda de una solución ante el conflicto, por medio de la aplicación de una proposición normativa, que debe ser justificada y fundada como fruto de una decisión.

PALABRAS CLAVE: Razonamiento jurídico, proposición normativa, interpretación jurídica, argumentación, motivación.

ABSTRACT: The present work will investigate in the most important aspects of the logic of the reasonable, in which the argument plays a fundamental role and while the juridical interpretation, is not alien. Legal reasoning seeks as the ultimate goal the search for a solution to the conflict, through the application of a normative proposition, which must be justified and founded as the result of a decision. The importance that it has for the juridical world, we can discover with just thinking, in the procedural law that has at last to regulate the form of the dispute or judicial controversy, in which the parties are thrown in a discussion where they argue and debate, In order that an impartial third party of credit to its positions and fails as dictated by the right.

KEYWORDS: Legal reasoning, normative proposal, legal interpretation, argumentation, motivation. 


\section{INTRODUCCIÓN}

Hay diversas formas de aproximarse al razonamiento jurídico o a la argumentación jurídica. Estas dos expresiones, se utilizarán, a partir de ahora, como sinónimas. En ese sentido, el concepto de razonamiento jurídico se entiende en ocasiones como una aplicación de la noción general de razonamiento (cualquiera que esta sea) al campo específico del Derecho; pero otras veces, se considera que el razonamiento jurídico es un tipo de razonamiento con características propias y cuya comprensión y manejo exigen un tratamiento diferenciado.

Es exigible entonces, perfilar una formulación inicial de la base del razonamiento jurídico en su expresión formulativa y en tal virtud, se cree que el juez, al iniciar el estudio del problema a resolver, debería de forma preliminar, estar convencido de acudir a un razonamiento lógico que evite decisiones manifiestamente contradictorias, vale decir, infracciones sustanciales a las reglas de la lógica, a fin de encontrar una decisión que sea esencialmente coherente.

Una vez definido, a grandes rasgos, el esquema lógico, deberá optar por una argumentación idónea, es decir, deberá recurrir a las proposiciones argumentativas que pretendan construir, paso a paso, la solución del problema que se le plantea. En ese sentido, la argumentación constituye la forma sustancial de resolución de conflictos y desde la perspectiva del derecho y razonamiento jurídico, esboza un enfoque de la evolución de la argumentación jurídica como disciplina autónoma.

Ahora, se tiene un esquema lógico y argumentos que sirven de base firme para nuestras proposiciones. Tiene lugar entonces, sobre lo anteriormente desarrollado, la exigencia de una adecuada interpretación no solo de la norma jurídica aplicable al caso concreto, sino también, de los hechos concernientes al caso. Al respecto, es prudente señalar que durante mucho tiempo, la exigencia interpretativa tuvo lugar, sobre las normas jurídicas como tales. Es decir, solo bastaba la interpretación jurídica correcta de la norma para llegar a una conclusión idónea.

La evolución del razonamiento jurídico como disciplina ha permitido constatar que la mera interpretación de la norma, resulta manifiestamente insuficiente. Y tal como se propone, la interrelación de los hechos resulta tan o más importante que la interpretación de la norma, dado que los hechos constituyen el insumo procesal fundamental al cual ha de recurrir el juzgador para posicionar su decisión. 
Aún más allá de la simple posición de considerar los hechos como materia a interpretar. Se refiere inclusive que el juez debe analizar todos y cada uno de los hechos a fin de materializar motivadamente su decisión, a diferencia de lo que convencionalmente la norma le exige al juez, es decir, inclinarse por estimar una valoración conjunta y razonada de los medios probatorios a efectos de explicar su decisión.

Por último, representa la esencia de todo el devenir intelectual de los pasos formulados en esta secuencia que se denominará "ejes del razonamiento jurídico idóneo en sede judicial", se tiene que la motivación, como expresión final de la decisión, va a representar la suma y ratio final, de todas las fases previas, a efectos de lograr el juez una legitimación de sus decisiones. Como solía decir el mismo Ferrajoli, "la base para el uso del poder del Juez reside en la aceptabilidad de sus decisiones" (Ferrajoli, 2001), y es a ello a donde debe apuntar el trabajo del juzgador en su fase motivacional, dado que una decisión judicial, por más discutible que fuera para la sociedad en general, se habrá ceñido a su deber de motivar dentro del Estado Constitucional si adopta un esquema idóneo no solo de justificación interna y externa de sus premisas, sino de lógica, argumentación e interpretación eficaces.

En suma, se aprecia una problemática esencialmente de construcción en el razonamiento jurídico. No resulta sencillo para el juez lograr el uso de todas las herramientas disponibles si no existe un entrenamiento formativo adecuado e idóneo en el tema. Y a ese propósito se han orientado diversas expresiones de autores e instituciones vinculadas al quehacer intelectual y de formación de los jueces.

Por lo tanto, la primera parte del presente documento, analizará de forma detallada la actuación de la lógica jurídica en el razonamiento judicial. La segunda parte, se enfocará en la interpretación jurídica como herramienta fundamental para las decisiones judiciales. Por último, la tercera parte examinará la argumentación en la praxis judicial, además de tener en cuenta su necesidad e importancia para el ratio decidendi; sin dejar de lado la motivación, que es otro aspecto fundamental que usan los jueces en cada caso. 


\section{LA LÓGICA JURÍDICA EN EL RAZONAMIENTO JUDICIAL}

\section{A. Lógica de lo razonable}

Mientras la lógica formal enseña las reglas del razonamiento para alcanzar la corrección, se descubre que esta misma corrección se presenta como fin inmediato del razonamiento (Cristancho Altuzarra, 2005). A todo razonamiento, se le atribuye un carácter instrumental porque permite conquistar distintos grados de certeza, que se puede clasificar como autoevidente (demostrable, plausible y aparente). En este sentido, tanto la lógica formal como la lógica dialéctica, deben integrarse y complementarse frente a las necesidades del discurso jurídico, para que sea aceptado como razonable, siempre que se encuentre sujeto a determinado criterios de corrección ya que debe establecer consideraciones sobre lo "justo".

Para la filosofía general, las tres operaciones del espíritu son, la aprehensión, el juicio y el razonamiento. Que permiten producir conceptos, que serán expresados por palabras o, unir o dividir conceptos y por último, como más elevada operación se encuentra al razonamiento, que posibilita agrupar proposiciones que buscan dar complejidad a nuestro pensamiento y de este modo fundamentar, nuestra acción o forma de pensar por medio de la argumentación, como justificación de nuestro actuar, y sobre los que se predica la verdad o verosimilitud de los mismos (Pachón Alonso et al., 2016). Se fundamenta tal actitud en la necesidad de una "razón" de tipo demostrativa, según las necesidades del "espíritu".

\section{B. La lógica jurídica}

La lógica jurídica no es igual a la lógica formal (meramente enunciativa, como las matemáticas que tienen una serie de supuestos indiscutibles); la lógica jurídica razona sobre situaciones concretas o contingentes, que operan mediante enunciados o proposiciones que dependen de la intención del operador, con la finalidad de convencer al público (Solari Merlo, 2015). Desde el punto de vista formal, examina las operaciones intelectuales del jurista, así como los productos mentales de esas operaciones: conceptos, divisiones, definiciones, juicios y raciocinios jurídicos, merecen en razón de su objeto específico el nombre de lógica jurídica. 
Además, a la lógica jurídica en el razonamiento judicial le incumbe el contenido de las normas jurídicas, sin embargo, no produce la decisión, sino es una herramienta para decir si esa decisión es razonada, es decir, prevé una serie de criterios para controlar la racionalidad de una decisión.

La lógica jurídica postula que debe rechazarse toda interpretación que conduzca a lo absurdo, y optar por la decisión más racional, es decir, convertir un derecho general abstracto a un derecho concreto. Este derecho concreto lo emite el Juez en una sentencia y para ello es necesario hacer un análisis lógico jurídico, una labor de interpretación, aplicar la ley y analizar que esa ley se mueva en el Sistema Jurídico.

El sistema jurídico por obligación tiene un solo ordenamiento jurídico, el cual guarda relación entre ellos mismos; se mueve bajo tres condiciones, que son a la vez sus características: unidad, coherencia y plenitud. (López, 2008)

\section{a) Unidad Jurídica}

El Criterio de Unidad es que la ley aplicable este en armonía y conforme a la constitución (para Kelsen la Constitución es: norma Superior; para Hart: Norma Fúndante). (Linde Paniagua, 2003). Si la norma está conforme con la constitución entonces se llama validez material; ejemplo, cuando la Sala Civil declara inaplicable el plazo para apelar, y prefiere la norma constitucional que regula los derechos del niño y de los padres, está dando una supremacía a la norma constitucional. La validez formal tiene que ver con su vigencia, el haber seguido el procedimiento constitucional para su elaboración, sanción, promulgación y publicación. En este sentido, cada tipo de norma en función de su fuente de producción va a ser igual a las que siguen su misma forma aunque el contenido sea distinto.

La noción de unidad del sistema atempas de ser importante para comprender la manifestación de los conflictos normativos, es una idea regulatoria del mismo que permite hacerlo coherente (Costa de Manzarredo, 2016). Esta unidad debe expresar coherencia y consistencia, ya que solo así puede expresarse un razonamiento racional y lógico. De otra manera no puede esperarse que las normas sean obedecidas, o que de alguna manera sean eficaces. 


\section{b) Coherencia jurídica}

La coherencia es una relación por la cual un conjunto de normas se subordina a (o subsume en) un conjunto de principios o valores relevantes; las normas coherentes satisfacen o son instancias de estos principios o valores (Romero Tamayo, 2000). Distingue entre principios y valores, que puede ser ambos, indistintamente, los referentes o parámetros de coherencia de un determinado conjunto de normas. Los valores son los estados de cosas deseables o fines valiosos perseguidos legislativamente, mientras que los principios son enunciados que establecen lineamientos generales de conducta tendientes a la obtención o concreción de los valores.

La coherencia se balancea entre la necesidad de especificidad del derecho (en cuanto a la necesidad de estipulación de normas detalladas) y la necesidad de que dichas normas sean instancias de principios generales (exigencia de universalidad y generalidad), toda vez que pocas personas pueden conocer el derecho en detalle, mientras que la mayoría pueden conocer los principios y valores generales del mismo. La función normativa de la coherencia puede entenderse como aquella función tendiente a resolver casos genéricos patológicos que puede poseer un sistema normativo. En este sentido, la coherencia resuelve problemas de antinomia, para lo cual la mejor solución se basa en tres principios que solo se los nombrará: Jerarquía, especialidad y Cronología. (Periñán-Pascual, y otros, 2011)

\section{c) Plenitud}

La plenitud es una de las características del ordenamiento jurídico, por consecuencia del razonamiento judicial. Se entiende por plenitud la propiedad por la cual un ordenamiento jurídico tiene una norma para regular cada caso. A la ausencia de una norma se le denomina generalmente laguna. (Salinas, 2004).

Aunque algunos autores sostienen que el ordenamiento jurídico suelen haber lagunas. De todos modos en cada ordenamiento jurídico por lo menos siempre deben estar presente los criterios que permiten solucionar las antinomias y lagunas que pueda haber.

Cuando en 1804 se publicó el Código Napoleón el nuevo cuerpo legal suscitó tal entusiasmo que se llegó a pensar que en el articulado 
del mismo se hallaba la solución a cualquier asunto. Ello dio origen al denominado "dogma de la plenitud del ordenamiento jurídico". (Galiano-Maritan, y otros, 2012). Es claro que tales opiniones estaban lejos de la realidad pues por minucioso que sea el redactado de la norma siempre serán inevitables las lagunas del Derecho. Puesto que en nuestro sistema no cabe el non liquet el juez, aplicador del Derecho, siempre tiene que pronunciar un fallo sobre cualquier cuestión que le sea sometida: basándose en la norma pertinente, si la hay, o llenar la laguna cuando ésta se presente.

En conclusión, el tema del razonamiento judicial puede ser considerado, cuando menos, desde dos puntos de vista: a) cuando genera hincapié en el aspecto sustancial por el que el juez trata de determinar o fijar las premisas para justificar su decisión final o conclusión; b) pone el acento sobre el aspecto exclusivamente formal, esto es, examinando su corrección lógica. De esta manera se analizó como a la lógica le interesa lo correcto en los razonamientos jurídicos. A ella incumbe la formulación de los preceptos para razonar correctamente.

\section{Interpretación jurídica}

La interpretación jurídica (o del derecho) es una actividad que consiste en enfocar el significado o alcance de las normas jurídicas y de los demás estándares que es posible encontrar en todo ordenamiento jurídico y que no son normas, como por ejemplo, los principios. En consecuencia, hablar de interpretación del derecho es igual a referirse a una actividad que comprende a todas las normas jurídicas, y no únicamente a las normas legales que produce el órgano legislativo. De ahí que la interpretación de la ley sea una especie de interpretación jurídica. Desde el punto de vista jurídico, entre los autores se encuentra diversas definiciones acerca de lo que es la interpretación.

Así, Guillermo Cabanellas de Torres afirma que:

"La Interpretación jurídica por excelencia es la que pretende descubrir para sí mismo (comprender) o para los demás (revelar) el verdadero pensamiento del legislador o explicar el sentido de una disposición." (Cabanellas de Torres, 2011)

En tanto, el ya clásico tratadista alemán Ludwig Enneccerus define la interpretación de la norma jurídica, en lo cual escribe lo siguiente: 
"Interpretar una norma jurídica es esclarecer su sentido y precisamente aquel sentido que es decisivo para la vida jurídica $y$, por tanto, también para la resolución judicial. Semejante esclarecimiento es también concebible respecto al derecho consuetudinario, deduciéndose su verdadero sentido de los actos de uso, de los testimonios y del "usus fori" reconocido y continuo. Pero el objeto principal de la Interpretación lo forman las leyes". (Atienza, 2003)

De igual manera, la conceptualización de la interpretación versa en dos sentidos con que los juristas han usado el término que ocupa. En primer lugar, se tiene el concepto restringido de interpretación, según el cual consiste en la atribución de significado a una formulación normativa en presencia de dudas o controversias en torno a su campo de aplicación. Corresponde al aforismo "In claris non fit interpretado": no se da ni puede ocurrir interpretación cuando un texto es claro y no deja dudas o controversias. En segundo lugar, está el concepto amplio de interpretación, en este caso el término se usa para referirse a cualquier atribución de significado a una formulación normativa, independientemente de dudas o controversias. Así, la interpretación se convierte en un presupuesto necesario para la aplicación del Derecho. (Ursúa, 2004).

Los dos conceptos anteriores parten ya de una idea de interpretación como actividad dianoética ${ }^{23}$, que es distinta de la definición. Aunque ambas consisten en la reformulación de una expresión, ésta última busca adscribir un significado con el que se supere la indeterminación semántica a priori, mientras que la interpretación tiende a reconstruir el significado a posteriori. Hay también casos en que el término interpretación se refiere al producto que resulta de dicho proceso, pero el sentido que presenta un mayor interés es el que considera a la interpretación como una actividad.

23 Dianoética: Es pensar a través de razones, no es solamente pura inteligencia, o sensibilidad, es pensamiento discursivo. No se limita a la experiencia que es la captación inmediata de la realidad como la noésis. La dianoética se desarrolla en el contexto del análisis, la descripción, la justificación o de la argumentación en este caso por medio de visualizaciones y perceptualizaciones. (Realir, Vargasir, y Flores, s.f.) 


\section{A. ¿Cuáles son los objetos de la interpretación jurídica?}

Otra ambigüedad que surge con respecto al término interpretación es aquella que se refiere a su objeto. En un sentido amplio puede ser objeto de la misma cualquier entidad capaz de portar un sentido, y en un sentido estricto sólo se interpretan entidades lingüísticas. En términos generales, Isabel Lifante afirma que hay tres respuestas a esta pregunta sobre qué es lo que se interpreta: 1) disposiciones jurídicas, 2) normas jurídicas, o 3) el Derecho. (Betti, 2015). Ninguna es una respuesta a plenitud satisfactoria. La primera dejaría fuera a la costumbre, la segunda ha levantado voces que consideran que las normas jurídicas son el producto de la interpretación y no tanto su objeto (para ellos lo que se interpreta son disposiciones o expresiones jurídicas), y la tercera traslada el problema a la búsqueda de un concepto claro y compartido de lo que es el Derecho. Dicha posición corresponde a quienes adoptan un concepto amplio de interpretación, e implica que interpretar es decidir el significado de un texto legislativo, no conocer sino producir una norma (por eso resulta un proceso necesario en todos los casos).

Por otro lado, la interpretación jurídica presenta otros objetos, los cuales se explicará:

a) Cuando se habla de interpretar un acto o comportamiento humano, interpretar a veces significa elaborar suposiciones en torno a los objetivos, a las razones o a las intenciones del sujeto agente; otras veces significa adscribir un sentido o un valor a la acción considerada. (Moreso, 2008). En particular, en el ámbito del discurso jurídico, "interpretar un hecho" (como homicidio intencional, en vez de muerte accidental) significa incluir ese hecho dentro de una cierta clase de hechos, o bien, subsumirlo a una norma, o incluso, calificarlo bajo el esquema de calificación que ofrece una norma para aplicarle así una consecuencia jurídica (por ejemplo, la sanción) que esa norma prevé.

b) Cuando se habla de interpretar un acontecimiento histórico o social, comúnmente "interpretar" conjeturar una relación de causa - efecto entre cierto hecho (o conjunto de hechos) condicionante y un hecho (o conjunto de hechos) condicionado.

c) Cuando se habla de interpretar un texto, significa atribuir sentido o significado a un determinado fragmento del lenguaje (vocablos, locuciones, enunciados). Sin embargo, conviene advertir, que a 
veces no se distingue (como sería oportuno hacerlo) entre la interpretación del texto en cuanto tal y la interpretación del comportamiento humano que produce ese texto. Naturalmente la línea de demarcación entre las dos cosas, es bastante sutil. No obstante, la distinción conceptual es clara; una cosa es preguntarse por el significado de las palabras, otra preguntarse sobre las supuestas intenciones del autor. Por ejemplo, una cosa es preguntarse si el vocablo "hombre" significa, en un contexto determinado, ser humano o bien masculino de la especie humana; otra cuestión es preguntarse si la persona, al decir "atención al que haga esto", entendía una advertencia o una amenaza.

La interpretación jurídica pertenece al género de interpretación textual. En expresiones como "interpretación jurídica", "interpretación del derecho", "interpretación de la ley", "interpretación de los actos (o documentos) normativos", "interpretación de normas" y otras similares, el vocablo "interpretación" denota, grosoo modo, o bien la actividad de averiguar o decidir el significado e algún documento o texto jurídico, o bien el resultado o producto de esa actividad: el significado del mismo. Que la interpretación sea una actividad de averiguación o de decisión es una cuestión controvertida, a la que diversas teorías de la interpretación ofrecen respuestas diferentes. (Massini Correas, 2004)

Naturalmente, existe una gran variedad de textos jurídicos sujeto a la interpretación; por ejemplo, leyes, reglamentos, contratos, testamentos, sentencias, actos administrativos, entre otros.

\section{B. Variedad de interpretes}

En el sistema jurídico vigente, la actividad interpretativa es ejercida prevalentemente, aunque no de manera exclusiva por algunos operadores típicos. En correspondencia con las diversidad figuras de los intérpretes, suele distinguirse entre interpretación auténtica, oficial, judicial y doctrinal.

a) Por interpretación auténtica se entiende, en un sentido amplio, la realizada por el autor mismo del documento interpretado (sin referencia alguna a la identidad del autor y a la naturaleza del documento); en este sentido estricto y por antonomasia, es la interpretación de la ley realizada por el mismo legislador mediante otra ley sucesiva (llamada ley interpretativa o ley de interpretación auténtica). 
b) Por interpretación oficial se entiende, la interpretación realizada por un órgano del estado en ejercicio de sus funciones.

c) Por interpretación judicial (o jurisprudencial) se entiende, la realizada por un órgano de la jurisdicción.

d) Por interpretación doctrinal se entiende, la que llevan a cabo los juristas; sobre todo, los profesores de derecho en obras académicas.

Conviene decir algunas palabras para poner en evidencia varios trazos distintivos entre la interpretación judicial y la interpretación doctrinal.

\section{a. Interpretación doctrinal e Interpretación judicial}

a) En primer lugar, la interpretación doctrinal y la judicial se distinguen por "su fuerza".

La interpretación doctrinal de una determinada disposición, de hecho, puede ser entendida como una recomendación, dirigida a los jueces para atribuir una disposición un determinado significado. En los sistemas jurídicos modernos, los profesionales del derecho no están jurídicamente habilitados para "decidir" el significado de los textos normativos: pueden hacer solamente sugerencias o propuestas. Sus propuestas interpretativas pueden, de hecho, ejercer influencias sobre las orientaciones jurisprudenciales de los tribunales (como pueden también no ejercerla); pero frecuentemente no tiene efectos jurídicos. Por esta razón, según un cierto modo de ver, los juristas deberían limitarse a enunciar los posibles significados de los textos normativos sin preescoger alguno. (Vargas-Chaves, 2013)

La interpretación judicial de una determinada disposición, por el contrario puede ser entendida como decisión, en torno a esa disposición. Las decisiones interpretativas de los jueces producen obviamente efectos jurídicos, aunque sean circunscritos, por regla general, al caso concreto definido.

b) En segundo lugar, la aproximación a la interpretación que es propia del jurista es distinta a la que es propia de los jueces. La interpretación doctrinal puede caracterizarse como una interpretación "orientada a los textos". Con esto quiere decirse, que comúnmente, 
lo juristas se preguntan (o se supone) sobre el significado de los textos normativos "en abstracto"; es decir, sin preocuparse de la solución de una específica controversia.

La interpretación judicial, por el contrario, puede definirse como una interpretación "orientada a los hechos", en el sentido de que el punto de partida de la interpretación judicial no es tanto el texto normativo como particular supuesto de hecho o controversia, del que se busca solución. Los jueces en suma, no se preguntan cuál es el significado de un texto normativo como un particular supuesto de hecho o controversia, del que se busca solución, sino que se preguntan si un determinado supuesto de hecho se encuentra o no dentro del campo de aplicación de una cierta norma. (Baldi Cabanillas, 2005)

Dicho en otros términos, el juez no puede limitarse a la interpretación textual. La aplicación del derecho requiere, juntas, la interpretación de las fuentes y la calificación del supuesto de hecho. A su vez, la calificación del supuesto de hecho presupone la verificación de los hechos de la causa.

En conclusión, la interpretación jurídica es la interpretación práctica por excelencia, su fin no es la toma del sentido auténtico en vistas a su contemplación intelectual, sino la determinación de la regla de comportamiento, aquél que interpreta un texto legislativo (en el amplio sentido) quiere llegar a saber en último lugar no solamente lo que el autor de ese texto ha dicho o ha querido decir (si es que esto puede saberse), sino cómo comportarse uno o cómo debe comportarse aquél que enseña (en el caso del profesor de derecho), o aconsejar (en el caso del abogado). Este método requiere que se enfoque a partir de la experiencia, del caso particular dada por la conducta intersubjetiva.

\section{LA ARGUMENTACIÓN EN LA PRAXIS JUDICIAL}

La argumentación está orientada fundamentalmente a persuadir, tal es el caso del Juez, quien pretenderá persuadir a las partes. Argumentar es estructurar un pensamiento que tiene una serie de reglas las cuales tienen que ser razonables, sirve para persuadir al destinatario de la veracidad o validez de una tesis. A la retórica hoy en día se le conoce como argumentación. (Iturralde, 1992). 
Antes se creía que argumentar era el clásico silogismo de Aristóteles, premisa mayor, premisa menor y conclusión, ahora no, la sentencia es una suma de argumentos, hay "n" respuestas por que el razonamiento jurídico es practico (aquel que admite discusión, sometida a la controversia, es pues interpretación) y demostrativo (lo que se afirma está sometido a prueba, está bajo el sistema de la libre valoración de la prueba, ya no de la prueba tasada, es pues valoración). Argumentar implica estructurar una secuencia coherente de pensamiento. Antes se decía que la sentencia era el clásico silogismo (premisa mayor, premisa menor y conclusión), hoy en día se dice que tiene una justificación. Será interna cuando se analiza la premisa mayor y la menor y se tiene una conclusión. Será externa cuando para validar (interpretar) Se debe justificar la premisa mayor y la premisa menor, con pruebas.

La argumentación jurídica es un proceso cognitivo especializado (teórico o practico) que se realiza mediante concatenación de inferencias jurídicas consistentes, coherentes, exhaustivas, teleológicas, fundadas en la razón suficiente, y con conocimiento idóneo sobre el caso objeto de la argumentación (Moreno Cruz, 2012). La argumentación jurídica se concretiza cuando se relaciona premisas, a la luz vinculante de los principios y demás cánones lógicos pertinentes, para obtener secuencial y correctamente, conclusiones que, según el caso, afirme o nieguen la subsunción del hecho en la hipótesis jurídica o afirmen o nieguen la validez o invalidez o la vigencia formal o real de la norma jurídica dada o afirmen o nieguen la pertinencia o impertinencia, o la aplicabilidad o inaplicabilidad o la compatibilidad o incompatibilidad de la norma jurídica al caso concreto.

Más allá de si la argumentación propia del derecho es deductiva o es una teoría de la argumentación, o ambas, lo cierto es que la argumentación jurídica, al menos la relativa a las decisiones judiciales, tiene, al menos, dos rasgos distintivos: su carácter práctico y su vinculatoriedad al derecho vigente.

Se dice que la argumentación propia del derecho tiene un carácter práctico porque versa sobre lo que puede o debe hacerse o no hacerse, no trata sobre el modo como son las cosas, sino sobre cómo deben ser; está formada por enunciados normativos que, como tales, no son susceptibles de ser calificados como "verdaderos" o "falsos". Para no entrar en la cuestión de cuál sería el mejor criterio para valorarlos (¿justos? ¿Buenos?), o si sería preciso hacer uso de una lógica 
deóntica para su tratamiento, simplemente se las llamará "correctos" o "incorrectos". (Iturralde, 1992)

Por otro lado, es evidente que no toda argumentación práctica es jurídica. En este sentido, no toda la argumentación práctica está regulada del mismo modo que la jurídica y, sobre todo, la conclusión de una argumentación jurídica (al menos su forma prototípica, que suele considerarse la de las decisiones judiciales) es vinculatoria.

Puesto que es el derecho una disciplina tan amplia y rica en matices, difícilmente podría tener exactamente el mismo modo de argumentar en todos los temas que le son propios. De acuerdo con (Atienza, 2003) existen al menos tres contextos jurídicos en los que se llevan a cabo argumentaciones. El primero es el de la "producción o establecimiento de normas jurídicas" (tanto en su fase prelegislativa, como en la legislativa, que es donde propiamente se manejan argumentos jurídicos, mientras que en la primera los argumentos, según Atienza, son más de tipo político y moral); un segundo contexto en que se realizan argumentos jurídicos es el de la "aplicación de normas jurídicas a la resolución de casos, bien sea ésta una actividad que llevan a cabo jueces en sentido estricto, órganos administrativos, en el más amplio sentido de la expresión, o simples particulares”. El tercer ámbito en que se realizan argumentos jurídicos es el de la "dogmática jurídica”, en la cual Atienza distingue tres funciones: "1) suministrar criterios para la producción del derecho en las diversas instancias en que ello tiene lugar; 2) suministrar criterios para la aplicación del derecho; 3) ordenar y sistematizar un sector del ordenamiento jurídico".

\section{A. Importancia de la argumentación}

Cuando una solución se presenta como la única admisible por razones de buen sentido, de equidad o de interés general, por su peso argumental tiende a imponerse en el campo jurídico, aunque se necesite recurrir a una argumentación especial, para mostrar su conformidad con las normas legales. La solución se vuelve aceptable solo, cuando ella va acompañada de cierto consenso social y de una argumentación jurídica suficientemente sólida.

El derecho es visto como un instrumento flexible y capaz de adaptarse a valores que el juez considera como prioritarios, para la sociedad, ya que su papel es conciliar estos valores con las leyes y 
las instituciones establecidas, de manera tal que con ello se ponga de manifiesto no sólo la legalidad, sino también el carácter razonable de sus decisiones. (Buenaga Ceballos, 2016).

Cuando se subraya la primacía de la ley, no solo se entiende que el juez solo está sometido a ella, sino que también se reconoce al poder legislativo la facultad única como creador de toda norma jurídica. Si se mantiene esta posición y no se distingue, entre normas generales y particulares, como diferenciara Kelsen, se observará que desde esta postura, el poder de interpretación del juez depende de la invocación a la voluntad del legislador, de la que nos hablara la escuela de la exégesis, como si esa voluntad continuara siendo la misma a pesar de la evolución técnica, moral o política que se hubiera producido en el transcurso del tiempo.

El juez no debe buscar la voluntad histórica del legislador que votó la ley, recurriendo a trabajos parlamentarios o los debatas que precedieron su votación; tiene que ir en búsqueda del legislador actual, para entender la norma según las circunstancias actuales que motivan su aplicación. Esto lleva a considerar que la acción de juzgar puede estar motivada en la idea de equidad; con la condición de que se pueda encontrar un fundamento jurídico satisfactorio. Pero para que llegué a una decisión que merece ser llamada equitativa ella debe responder a ambas circunstancias: ser oportuna y socialmente útil.

En un pleito judicial cada una de las partes expone sus motivos, fundados en la jurisprudencia más benigna o en planteos doctrinarios, con la intención de argumentar y favorecer su particular posición, con la intención de motivar en tal sentido la decisión del juez, y como resultado lograr su convencimiento. La solución jurisdiccional es producto de un proceso de análisis, en el que cada paso debe asumir el anterior y mejorarlo. Desde una perspectiva fenomenológica, se identifican cuatro regiones sentenciales, las que presentan una totalidad discursiva de entidad ontológica.

Tales regiones a considerar son: 1) hechos / derechos; 2) inserción sentencial; 3) argumentación y 4) justificación / motivación.

Respecto de los hechos se dice, que en todo expediente judicial, se encuentra una referencia a situación fácticas constituidas por la situación litigiosa y por la producción de aquella prueba que han realizado las partes en el proceso, que permiten demostrar 
los hechos y sirven para dar un fundamente al derecho del que se pretende ser objeto (Amaya, 2011). Los hechos que van a tener entidad o valor para la sentencia serán sólo, aquellos que recibirán una inserción sentencial, al ser estimados como altamente importantes para fundamentar una resolución.

Este primer y segundo paso, pueden ser incluidos dentro de la llamada justificación interna, con relación al acto de sentenciar, en la medida que las pruebas, sobre los hechos y los derechos alegados, conforman un núcleo inescindible, que le permite al juzgador construir convicciones. Mientras que la justificación externa, está dirigida al auditorio, que define como aquellos a quienes el orador quiere influir para lograr su convencimiento, con la exposición de motivos.

Si bien puede perderse de vista el perfil antropológico del auditorio para pasar a ser un objeto teórico, en la medida que no solo teoriza sobre él, sino que además se transforma en aquello a lo que se dirigen nuestros actos de habla presentes o futuros. El auditorio juega un papel importante en el discurso en general, en la medida, que este debe ser adaptado según aspectos cualitativos y cuantitativos, ya que entran a jugar circunstancias que se pueden hacer valer en la misma argumentación. Específicamente el auditorio forense posee características particulares, porque se lo puede definir como universal en la medida que reconoce la atemporalidad de las sentencias y el juego argumental que propone; de tal forma que se deben ponderar las distintas líneas argumentales en función de la posibilidad de éxito o fracaso y de crítica o aceptación, que el orador tiene que imaginar al momento de la creación discursiva.

Dicha justificación externa está compuesta por la tercera región que se denomina argumentación que se estructura como una razonamiento silogístico de carácter práctico prudencial, que toma para su construcción modelos o paradigmas de conductas, socialmente valiosas (Amaya, 2011). Claro que esta región puede ser pasible de vicios como la equivocación, la mala disposición argumental o la incoherencia, que provocan la incomunicación, por imposibilidad de decodificar el discurso, de tal manera que suscita el rechazo por parte del auditorio.

La cuarta región se la denomina: motivación, que resulta ópticamente incognoscible, porque tiene que ver con lo subjetivo; sin embargo, el discurso nos permite descubrir sus contornos. 
Los motivos se basan en tres elementos diferentes: ideológico (política o religiosa), axiológico (criterios valorativos, valores - antivalores), ambas pertenecientes en los objetos culturales; mientras que el tercer elemento es llamado idiosincrático y se refiere a concepciones, pasiones, sensaciones, deseos, ansiedades, temores y triunfos; que son parte de la opción que una persona toma y son característicos del ser humano.

Cada una de estas regiones fundamentan el acto voluntario de toma de decisiones en los que se puede privilegiar distintos aspectos como: 1. Adhesión voluntaria a principios generales de conducta. 2. Obediencia a determinadas prescripciones. 3. Reclamos exteriores o necesidades sociales (Buenaga Ceballos, 2016)

En definitiva, si alguien desconociera el motivo que guía su discurso o siquiera le importara, se encontraría ante una situación de ignorancia operacional, eminentemente peligrosa y totalmente injustificable si se la considera, en relación al discurso jurídico. (Ferrer Beltrán, 2015).

\section{B. Necesidad de la argumentación}

La labor de los abogados es ciertamente técnica, pues consiste en usar ciertos medios para alcanzar un resultado a partir de una situación inicial dada. Mientras que la de los jueces consiste en utilizar normas generales para justificar decisiones particulares y concretas.

Para mayor abundamiento se dice, que tanto los jueces como los abogados utilizan reglas técnicas explicitas dadas por el Derecho Procesal. Así los distintos operadores jurídicos recurren al derecho de fondo con la intención de argumentar jurídicamente, para instar la acción o en función de un requerimiento de la parte, como es propio en la actividad de los abogados, y que los jueces también deben realizar al momento de fundamentar sus decisiones.

Se reconoce que todo acto humano, sin excepción alguna, es susceptible de ser percibido desde la perspectiva del juez, del abogado o del jurista y valorado y juzgado como acto jurídicamente significativo.

De todo acto humano exterior, perceptible por los sentidos, se puede predicar que este constituye: a) El ejercicio de una potestad. b) El padecimiento de un deber jurídico. c) La violación de un deber 
jurídico. d) El padecimiento de una sanción aplicada por un órgano jurisdiccional competente (Buenaga Ceballos, 2016).

Lo propio de la tarea del juez y del abogado en el fondo es la misma desde distintos prismas de la realidad, la que se encuentra caracterizada, por predicar la significación jurídica como potestad o prestación, o como entuerto o sanción. Para lo cual necesitan valorar desde aquellos valores vigentes en la comunidad, como así también, desde los valores vigentes en las normas jurídicas.

La experiencia jurídica comienza, para los jueces y abogados desde el contacto con las partes; no así para estas últimas, que se inicia en una etapa previa (ejemplo: desde la firma del contrato). Desde el conocimiento fáctico de la realidad, los jueces y abogados otorgan al hecho o acción significación jurídica, al valorar la conducta.

Sin embargo, esto no es todo; falta que el juez y el abogado le otorguen una significación normativa, a la situación descrita por las partes; lo que implica ahora, una selección normativa susceptible de ser aplicada al caso, para el que se deberá tener encuenta los aspectos relevantes del hecho jurídico.

De este modo la argumentación jurídica se examinó de manera detallada, como la justificación de una decisión del órgano jurisdiccional, que se presenta como una solución que se constituye como síntesis del proceso dialéctico que enlaza ambos aspectos - norma - conducta - por medio de la interpretación jurídica. En el cual la argumentación juega un papel destacado en esta instancia, porque actúa como la base del razonamiento que será utilizado en la toma de decisión, por parte del magistrado. Este movimiento de síntesis, comienza con una tarea de clarificación del lenguaje normativo y finaliza con la búsqueda de la corrección del sentido jurídico en la decisión judicial.

\section{CONCLUSIONES}

A modo de conclusión se remarca que explorar la razón jurídica implica traspasar el campo de la lógica tradicional, en busca de la razón vital e histórica o mejor dicho establecer una lógica de la acción, ya que la vida humana es el reino de la acción y la libertad. En este sentido, tanto la lógica formal como la lógica dialéctica, deben integrarse y complementarse frente a las necesidades del discurso jurídico, que 
pretende ser razonable y alcanzar cierto grado de corrección. Así la elaboración de una conclusión o solución, implica la necesidad de reconocer, la validez de ciertas reglas lógicas, que serán necesarias a la hora de producir el razonamiento. Este es el motivo por el cual el silogismo dialéctico, se funda en la verosimilitud, ya que necesita de buenas razones que justifiquen las decisiones. Debiéndose destacar la doble función objetivante de la norma como parte del conocimiento jurídico, tanto lógico como axiológico. Que obliga a observar el lenguaje normativo, cuyo significado racionalmente inteligible permite categorizar las acciones humanas.

Es claro, no existe un concepto único de interpretación jurídica. Probablemente, la fuente de la riqueza del debate teórico que en torno suyo se ha desarrollado, resida precisamente en las ambigüedades del término. La interpretación jurídica se lleva a cabo por los actores que la realizan. Estos actores-intérpretes son seres humanos, por consiguiente, sujetos que realizan esa tarea o actividad. Y, por lo tanto manifiestan o expresan versiones subjetivas en esa labor de interpretación. La afirmación de que se puede realizar una labor objetiva, no es cierta. Lo que sí es cierto es que el sujeto puede hacer el intento orientado en el sentido de que sus creencias, estereotipos, ideologías, intereses, etc., pesen lo menos que pueda (autocontrol) al momento de verter su decisión, opinión o criterio en ese documento llamado dictamen, sentencia, informes, etc.

Argumentar es razonar nuestras proposiciones para sustentarlas válidamente sin criterios de arbitrariedad. No es necesario que un texto sea oscuro para interpretarlo, pues interpretar es dar significado a una formulación normativa. De igual manera, no se puede separar la interpretación de la argumentación pues una es el presupuesto de la otra. Como consecuencia. Los textos jurídicos contienen, en muchos casos, varias alternativas de interpretación; la elección de una de ellas no puede apoyarse en razones arbitrarias, por lo que para justificar la decisión el argumento es la clave. La justificación implica sustentar la opción interpretativa en una base argumentada coherente y aceptable en condiciones de racionalidad. 


\section{REFERENCIAS BIBLIOGRÁFICAS}

Amaya, A. (2011). Virtudes, argumentación jurídica y ética judicial, Diánoia, vol. LVI, núm. 67. ISSN: 0185-2450. Universidad Nacional Autónoma de México. 135 - 142.

Atienza, M. (2003). El sentido del Derecho. Barcelona: Editorial Ariel S.A.

Baldi Cabanillas, R. R. (2005). La teoría de la interpretación judicial en Cossio y Betti: Coincidencias y actualidad de dos perspectivas contemporáneas, Revista Chilena de Derecho, Vol. 32, No. 1. 139 - 168.

Betti, E. (2015). Teoría de la interpretación jurídica. Santiago de Chile: LexisNexis Chile. 55 - 79.

Buenaga Ceballos, Ó. (2016). Razonamiento y Agumentación Jurídica (2): El discurso jurídico como caso especial del discurso práctico general de Alexy, Dykinson, S.L. 109 - 124.

Buenaga Cevallos, O. (2016). Razonamiento y Argumentación jurídica (1): La retórica jurídica de Perelman, Dykinson, S.L. 99-108.

Cabanellas de Torres, G. (2011). Diccionario Jurídico Elemental, Argentina: Ed. Heliasta. S.R.I.

Costa-de-Manzarredo, A. (2016). El fundamento jurídico para la creación de un sistema jurídico europeo en materia de Derecho contractual. Revista de Derecho UNED, No 19. 617 - 652.

Cristancho Altuzarra, J. G. (2005). Lógica de la razón sistémica, Franciscanum Revista de las ciencias del espíritu, No 139. 143 - 151.

Ferrajoli, L. (2001). El Derecho como sistema de garantías. En Derechos y garantías: la ley del más débil, Madrid: Ed. Trotta. 26.

Ferrer Beltrán, J. (2015). Apuntes sobre el concepto de motivación de las decisiones judiciales. Universidad de los Andes. 57-76.

Galiano-Maritan, G., y González-Milián, D. (2012). La integración del Derecho ante las lagunas de la ley. Necesidad ineludible en pos de lograr una adecuada aplicación del Derecho, Universidad de La Sabana. 431-438. 
Iturralde, V. (1992). Argumentación y razonamiento judicial, University of the Basque Country (UPV/EHU), Vol. 7, No. 16/18. 1049 - 1078.

Linde Paniagua, E. (2003). Sistema de Distribución de Competencias y Racionalización del Sistema Normativo, Revista de Derecho de la Unión Europea. 259 - 286.

López, F. (2008). Hacia un espacio europeo de aprendizaje para toda la vida. Evolución y desarrollo de la educación permanente en la Unión Europea, Revista universitaria de pedagogía social, No 15. 123 - 135.

Massini Correas, C. L. (2004). Determinación del derecho y directivas de la interpretación jurídica, Revista Chilena de Derecho, Vol. 31, No. 1. 155 - 168.

Moreno Cruz, R. (2012). Argumentación jurídica, por qué y para qué, Boletín Mexicano de Derecho Comparado, Vol. 45, No 133. Universidad Autónoma de México. 165 - 172.

Moreso, J. J. (2008). Dos concepciones de la interpretación jurídica, Isonomía. Revista de Teoría y Filosofía del Derecho, No 29.7 - 14.

Pachón Alonso, L. A., Parada Sánchez, R. A. y Chaparro Cardozo, A. Z. (2016). El razonamiento como eje transversal en la construcción del pensamiento lógico, Praxis \& Saber, Vol. 7, No. 14. 50 - 75.

Periñán-Pascual, C., y Mairal-Usón, R. (2011). The Coherent Methodology in FunGram KB, Revista Onomázein. 13 - 33.

Realir, R., Vargasir, J. y Flores, M. (s.f.). ArquePoética. Obtenido de Dianoética: http://arquepoetica.azc.uam.mx/escritos/dianoetica.html

Romero Tamayo, J. (2000). Algunas ideas sobre la Coherencia, Nómadas, No 2. 4 - 20.

Salinas, C. (2004). Plenitudo Legis Dilectio, Teología y Vida, Vol. 45, No 1.157 - 167.

Solari Merlo, M. (2015). La racionalidad de la ciencia y (en la ciencia del) derecho, Revista de Derecho UNED. 1 - 4. 
Ursúa, J. F. (2004). Interpretación jurídica: una propuesta de esquematización de planteamientos, Instituto Tecnológico Autónomo de México. $17-35$.

Vargas-Chaves, I. (2013). Elementos doctrinales para el estudio de la argumentación como eje del control judicial, Prolegómenos. Derechos y Valores, Vol. 16, No. 32. 235 - 246.

Recibido: 5/02/2017

Aprobado para publicación: 27/05/2017

Mabell Abigail Lagla Pillajo: Investigadora jurídica Cevallos \& Noboa.

Correo electrónico: laglamabell@gmail.com 